\title{
Integrated System Health Management: Foundational Concepts, Approach, and Implementation
}

\author{
Note: Submitted to the Focused Session on Integrated System \\ Health Management (ISHM) organized by Fernando Figueroa
}

\section{Authors:}

Fernando Figueroa, NASA Stennis Space Center, MS

Fernando.Figueroa@nasa.gov, 2286882482.

\section{Introduction}

Implementation of integrated system health management (ISHM) capability is fundamentally linked to the management of data, information, and knowledge (DIaK) with the purposeful objective of determining the health of a system. It is akin to having a team of experts who are all individually and collectively observing and analyzing a complex system, and communicating effectively with each other in order to arrive to an accurate and reliable assessment of its health. We present concepts, procedures, and a specific approach as a foundation for implementing a credible ISHM capability. The capability stresses integration of DIaK from all elements of a subsystem. The intent is also to make possible implementation of on-board ISHM capability, in contrast to a remote capability. The information presented is the result of many years of research, development, and maturation of technologies, and of prototype implementations in operational systems (rocket engine test facilities). The paper will address the following topics:

1. ISHM Model of a system

2. Detection of anomaly indicators.

3. Determination and confirmation of anomalies.

4. Diagnostic of causes and determination of effects.

5. Consistency checking cycle.

6. Sharing of health information

7. Sharing of display information

8. Storage and retrieval of health information

9. Example implementation

\section{ISHM Model of a System (Architecture and Taxonomy)}

The ISHM model encompasses DIaK needed to achieve ISHM capability.

Data is available from sensors. Distribution of DIaK associated with physical elements of a system gives rise to an information architecture, specifically where intelligent processes at various levels of granularity are executed (See Figure 1). The architecture embodies intelligent sensor and component processes (valve, tank, etc.) at the lowest level, and intelligent processes associated with combinations of sensors and components (or subsystems) at higher levels. Higher levels of abstraction are embodied at higher 
architectural levels, where these obtain data and information from lower levels and execute process models that essentially allow for checking the consistency of lower level information. Hence, data and information flow first from lower levels to higher levels. At each level, consistency checks are done using knowledge (process models). Results of the consistency checks flow to levels below, eventually reaching the sensors and components, in order to help these elements improve their assessment of health. Results of the consistency check flow to levels above for additional checks. In this manner, consistency checks at all levels are used to determine the health of sensors and components (hence the system).

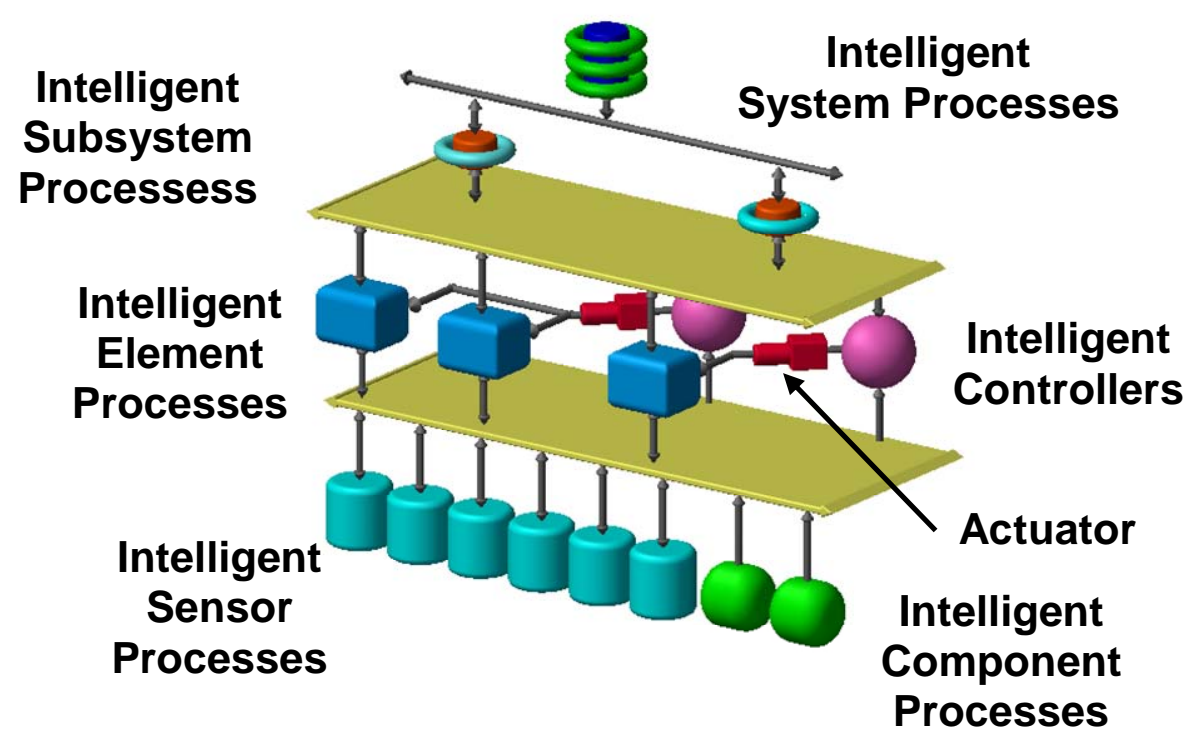

Sensor Processes utilize data; hence, data must be available at each intelligent sensor process. Processes within intelligent sensors must assess the quality of the data and the health of the sensor. These processes may reside in physical intelligent sensors or virtual ones (that turn legacy sensors into intelligent ones).

Element Processes (or component processes) can be encapsulated within an element such as a tank or valve. Eventually, Element Processes must have available data and information from sensors that are installed specifically as an integral part of that element (e.g. position feedback on a valve).

Subsystem Processes consume information from Sensor and Element Processes (primarily health, but also transducer data sheets and data); and update health related parameters on sensors and elements. These processes also might provide inputs to external predictive models and get back their outputs.

System Processes and higher levels are similar to subsystem processes, except that they will require data and information from lower levels more sporadically. They will primarily consume health information and push back down information to improve health assessment at lower levels. 


\section{Detection of Anomaly Indicators}

\section{Indicators at Sensors}

Indicators that can be detected with localized sensor information and data. For example, excessive noise, spikes, etc. These indicators can lead to detection of anomalies, e.g. unattached thermocouple (combination of high noise, perhaps $60 \mathrm{~Hz}$ interference, and time response that is not consistent with the measurand's time constant). However, for anomaly detection, additional information from the process in which the sensor participates is often needed; e.g. the time constant of the measurand.

\section{Indicators at Components}

Generally, an anomaly indicator at a component is a result of reasoning that involves data and information from sensors and models of processes in the component e.g. pressurized tank, tank fill, valve state, etc. In this case, what is needed are sensor data, a measure of the quality of the data, and sensor health (perhaps just good, suspect, and bad health states), and process models to detect anomaly indicators by checking consistency of sensors and model.

The architecture, standards, and object classes should allow automatic (standardized) access of information to run the process models, and make models outputs available to other models for further inferences.

\section{Detection and Confirmation of Anomalies}

Detection and confirmation of anomalies are done through use of process models that involve a sensor, a component and associated sensors, and combinations of components and sensors that might be defined as subsystems for the application of specific process models (strategies).

\section{Anomalies at Sensors}

Some anomalies might be determined using localized data and information, however, confirmation of an anomaly will come from models that incorporate one or more components. The approach to confirmation is to let the sensors know when their health assessment is not consistent with the assessment at higher levels.

\section{Predictive Process Models (PPMs)}

Predictive models might be considered as specialized "virtual” sensors that provide predicted sensor readings. PPMs are considered to be a special type of virtual intelligent sensors.

The highest priority of ISHM is to determine sensor anomalies.

\section{Anomalies at Components}

Anomalies at components, e.g. valve stuck, can be determined with data and information from the valve, its sensors, and a process model describing a stuck condition. However, 
just as in the case of sensors, if this assessment is not consistent with higher level models (that include the valve), it will need to be communicated to the valve.

The second highest priority of ISHM is to determine component anomalies.

\section{Anomalies at Subsystems, Systems, etc.}

Methods that can capture anomalies at some subsystem or system (e.g. leak) level could be treated as PPMs. The output should be treated as its own virtual sensor that simply determines if a system has an anomaly.

\section{Diagnostic of causes and determination of effects}

Detection of events and determination of causes and effects should be inferred and analyzed within the ISHM Model. Sensor information such as rate of increase or decrease, and health parameters (noisy, etc.) should be provided to the ISHM model. Sensor data is needed for display purposes. Initially, one could build two models; one for ISHM and another for Display. Other display applications might use data (values + health) provided the sensors and the ISHM Model.

\section{Consistency checking cycle}

This addresses the problem of where to begin the cycle of consistency checking that leads to anomaly (indicators) detection and diagnostics. Locally assessed health information should be done first to feed higher level process models. At every level upward, reassessment of health information should flow down. The following cycle should be implemented:

1. Initiation: All sensor local health assessment done.

2. Level 1 process models and re-assessment of sensor health (each sensor should have a consistency value for each process in which it participates with a value of consistent, not defined, or not consistent), However, a Sensor could push-back at process model that indicates it is faulty when other models indicate otherwise.

3. Assessment of component health based on good sensor information and process models.

\section{Sharing of health information}

"Real-Time" health information from sensors and components should be shared using the IEEE 1451.1 standard. Other health information should be shared using the OSA-CBM standard.

\section{Sharing of Display Information}

Display information should include health and data. It should also include "real time" and "historic information."

\section{Storage and retrieval of health information}

Along with data, a history of health information should be stored for retrieval by any user. 


\section{Example Implementation}

An example implementation constituting a complete ISHM capability will be described. The implementation will include software and hardware developed in recent years; and it will describe an application to an operational system.

\section{References}

1. F. Figueroa and J. Schmalzel, "Rocket Testing and Integrated System Health Management”, Chapter in the book Condition Monitoring and Control for Intelligent Manufacturing (Eds. L. Wang and R. Gao), pp. 373-392, Springer Series in Advanced Manufacturing, Springer Verlag, UK, 2006.

2. Fernando Figueroa, Randy Holland, and David Coote, "NASA Stennis Space Center Integrated System Health Management Test Bed and Development Capabilities,” SPIE Defense \& Security Symposium, Sensors for Propulsion Measurements Applications (OR13), April 17-21, 2006, Gaylord Palms Resort and Convention Center, Orlando (Kissimmee), FL, USA.

3. John Schmalzel, Fernando Figueroa, Jon Morris, Shrekanth Mandayam, Robi Polikar, “An Architecture for Intelligent Systems Based on Smart Sensors,” IEEE Transactions on Instrumentation and Measurement, Vol. 54, No. 4, August 2005, pp. 1612-1616.

4. Fred M. Discenzo (Rockwell Automation, Cleveland, $\mathrm{OH}$ ), William Nickerson (Oceana Sensors, State College, PA), Charles E. Mitchell (Boeing Phantom Works, Long Beach, CA), Kirby J Keller (Boeing Phantom Works, Saint Louis, MO), “Open Systems Architecture Enables Health Management for Next Generation System Monitoring and Maintenance Development Program” -White Paper, 20002? www.osacbm.org.

5. Matt Davidson and John Stephens, "Advanced Health Management System for the Space Shuttle Main Engine,” 40th AIAA/ASME/SAE/ASEE Joint Propulsion Conference, Fort Lauderdale, FL, July 11-14, 2004.

6. www.gensym.com

7. Lee, K., “Sensor Networking and Interface Standardization,” Proc. 18th IMTC, 2001, pp. 147-152.

8. Lee, K., "Smart Transducer Interface Standards for Condition Monitoring and Control of Machines", Chapter in the book Condition Monitoring and Control for Intelligent Manufacturing (Eds. L. Wang and R. Gao), pp. 347-372, Springer Series in Advanced Manufacturing, Springer Verlag, UK, 2006.

9. Exception Analysis for Multimissions - Livingstone Integration,” in proceedings of 2004 Machinery Failure Prevention Technology Conference, edited by H. G. Park.

10. www.ni.com

11. Mahajan, A., Chitikeshi, S., Bandhil, P., Utterbach, L. and Figueroa, F., "Intelligent Sensors - An Integrated Approach,” Proceedings of the 5th International Workshop on Structural Health Monitoring, Stanford University, California, September 12-14, 2005.

12. Chitikeshi, S., Bandhil, P., Utterbach, L., Mahajan, A. and Figueroa, F., "Intelligent Sensors - Strategies for an Integrated Systems Approach," Proceedings of the ASME IMECE2005, Orlando, Florida, November 6-11, 2005. 
13. Kuipers, B.J., "Reasoning With Qualitative Models”, Artificial Intelligence, Vol. 59, pp. 125-132 (1993).

14. Mahajan, A. and Figueroa F., "Dynamic Across Time Autonomous - Sensing, Interpretation, Model Learning, and Maintenance Theory," Mechatronics, Vol. 5, No. 6, pp. 665-693 (1995).

15. Park, H. G., Zak, M., "Grey-box Approach for Fault Detection of Dynamical Systems,” ASME Journal of Dyn. Sys., Meas., \& Control, Vol. 125, pp. 451-454 (2003).

16. Park, H. G., Cannon, H., Bajwa, A., Mackey, R., James, M., Maul, W., “Hybrid Diagnostic System: Beacon-based

17. Park, H. G., Mackey, R., James, M., Zak, M., Baroth, E., “BEAM: Technology for Autonomous Vehicle Health Monitoring," in proceedings of 2002 CS/APS/PSHS/MSS JANNAF Meeting, edited by H. G. Park.

18. Malloy, D.J., Biegl, C., Zakrajsek, J.F., Meyer, C.M. and Fulton, C.E., "Development of a Near Teal-Time Turbine Engine Testing Diagnostic System Using Feature Extraction Algorithms,” in proceedings of 13th Int. Symp. on Air Breathing Engines1997, edited by D. J. Malloy.

19. Ramohalli, G., 1994, "Honeywell's Aircraft Monitoring and Diagnostic Systems for the Boeing 777,” Proceedings of the 17th Symposium on Aircraft Integrated Monitoring Systems, pp. 69-71, 73-87.

20. Jue, F. and Kuck, F., 2002, "Space Shuttle Main Engine (SSME) Options for the Future Shuttle,” Proceedings 38th AIEE/ASME/SAE/ASEE Joint Propulsion Conference and Exhibit, AIAA 2002-3758.

21. Schweikhard, K. A., Theisen, J., Mouyos, W. and Garbo, R., 2001, “Flight Demonstration of X-33 Vehicle Health Management System Components on the F/A18 Systems Research Aircraft,” NASA/TM-2001-209037.

22. Prosser, W. H., Allison, S. G., Woodard, S. E., Wincheski, R. A., Cooper, E. G., Price, D. C., Hedley, M., Prokopenko, M., Scott, D. A., Tessler, A. and Spangler, J. L., 2004, "Structural Health Management for Future Aerospace Vehicles," Proceedings of the 2nd Australian Workshop on Structural Health Management.

23. Bajwa, A. and Sweet, A., 2002, "The Livingstone Model of a Main Propulsion System,” RIACS Technical Report 03.04. Available at http://www.riacs.edu/trs/.

24. Fernando Figueroa, Randy Holland ， John Schmalzel, and Dan Duncavage, "Integrated System Health Management (ISHM): Systematic Capability Implementation,” SAS 2006 - 2006 IEEE Sensors Applications Symposium Houston, Texas, USA, 02-07-06.

25. Robinson, P., Shirley, M., Fletcher, D., Alena, R., Duncavage, D., and Lee, C., "Applying Model-Based Resoning to the FDIR of the Command and Data Handling Subsystem of the International Space Station,” ISAIRAS 2003, Nara, Japan, 2003.

26. Edward N. Brown, and Bala Chidambaram, "Applying Health Management Technology to the NASA Exploration System-of-Systems,” AIAAA 2005-6624, Space 2005, 30 August-1 September 2005, Long Beach, California. 